\title{
The Elaboration of Cultivating Learners' English Communicative Competence in China
}

\author{
Yuxiang Zhang ${ }^{1} \&$ Jiling Wang ${ }^{1}$ \\ ${ }^{1}$ The Foreign Languages Department, Hefei Normal University, China \\ Correspondence: Yuxiang Zhang, The Foreign Languages Department, Hefei Normal University, (Jinxiu \\ Campus), 1688, Lianhua Rd., Hefei Economic and Technological Development Zone, Hefei, 230601, Anhui \\ Province, China. Tel: 86-551-283-3720. E-mail: zhangyuxiang@hftc.edu.cn
}

$\begin{array}{ll}\text { Received: August 15, } 2012 & \text { Accepted: October 8, } 2012 \text { Online Published: October 23, } 2012 \\ \text { doi:10.5539/elt.v5n12p111 } & \text { URL: http://dx.doi.org/10.5539/elt.v5n12p111 }\end{array}$

\begin{abstract}
The communicative competence is the ultimate goal of the Communicative Language Teaching (CLT), which is thought to be the eclectic approach in the place of other approaches and methods and which begins to gain momentum in the recent years. Hence, the comprehensive understanding of the communicative competence is prerequisite to the cultivation of the students' communicative competence. This study did some investigation with a view to elaborating the cultivation of learners' English communicative competence in China. It did an investigation into 9 senior middle schools in Anhui, China. 9 schools in three areas were visited. About 400 students were asked to do a questionnaire on the self-assessment of their English communicative competence. 27 English teachers and 9 headmasters/mistresses were interviewed about their teaching practice in senior middle school. Based upon the data collected from the investigation, the paper puts forward some problems as well as some suggestions in the implementation of the cultivation of students' communicative competence.
\end{abstract}

Keywords: communicative competence, cultivating communicative competence, Chinese senior middle school students, senior English

\section{Introduction}

In the early 1970s, the Communicative Language Teaching (CLT) was developed by D. A. Wilkins (1972) and some other British linguists to take the place of the situational language teaching which was based upon the structural linguistics. Ever since then, CLT has been the hot topic on the lips of the language teachers with a lot of disputes in terms of its concept and its implementation. Today, many language teaching methodologists subscribe more or less consciously to one or other aspect of communicative teaching. Although it has incorporated many of the characteristics of earlier language teaching innovations, CLT has avoided the narrowness and dogmatism of the method concept and covers a wider range of components (Stern, 1999). And it advances the claim that its ultimate goal is to cultivate the communicative competence of the learners. The significance of CLT lies in that it provides "one possible solution to bridge the gap between classroom language teaching and real life language use" (Wang, 2000).

\subsection{Communicative Competence}

Then what is the communicative competence? What should learners do and why should learners possess communicative competence? It is necessary to review the definitions of "communicative competence" that have been widely quoted:

The ability not only to apply the grammatical rules of a language in order to form grammatically correct sentences but also to know when and where to use these sentences and to whom. (Richards \& Rodgers, 2000)

Learning a second language was similarly viewed by proponents of CLT as acquiring the linguistic means to perform different kinds of functions. (Richards \& Rodgers, 2000)

... learners need to acquire a general communicative ability, which will enable them to cope with everyday situations. ... people who want to prepare themselves, in a general way, to be able to communicate socially on straightforward everyday matters with people from other countries who come their way, and to be able to get around and lead a reasonably normal life when they visit another country (Littlewood, 2000). 
1) knowing whether or not something is formally possible;

2) knowing whether something is understandable to human beings;

3) knowing whether something is in line with social norms;

4) knowing whether or not something is in fact done: Do people actually use language in this way? (Hymes, 1979)

From the above quotations, we know that, as Hymes (1972) put it, in addition to linguistic competence, the native speaker has another rule system. That is, $\mathrm{s} /$ he knows intuitively what is socially appropriate or inappropriate and can adjust his language use to such factors as the topic, situation, and human relations involved: in short, s/he possesses "communicative competence". In lay terms, the communicative competence includes both the knowledge about the language and the knowledge about how to use the language appropriately in communicative situations. The knowledge about the language refers to the form of the language, which is roughly equivalent to Chomsky's linguistic competence which serves as the basis for the production of meaning, i.e. language use, whereas the knowledge about how to use the language appropriately in communicative situations places emphasis upon the proper communicative use of the language in the real life situations which can be labeled as the communicative competence. Hence, it is obviously clear that the communicative competence includes the linguistic competence and the communicative competence with both being indispensable to each other, the lack of either of which will lead to failure in the effective communication. The authors think that communicative competence is the core of the CLT and that correct and comprehensive understanding of the communicative competence is quite crucial to the understanding of the essence of this approach along with its implementation in the real teaching practice.

\subsection{Communication and Competence}

First, what is communication? According to the Longman Dictionary of Contemporary English (1997), communication is "the process by which people exchange information or express their thoughts and feelings." It's a kind of interaction between the sender and receiver, which can be shown in Figure 1 below:

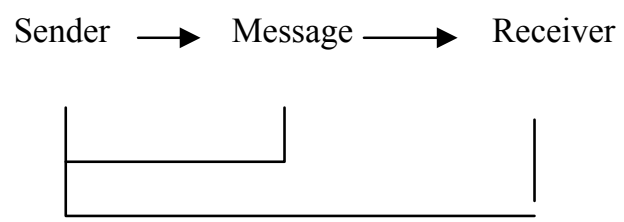

Figure 1. The interaction between the sender and receiver

And in Figure 1, unlike the traditional mode of interaction which is quite unidirectional, this kind of interaction, whether symmetrical or asymmetrical, is bidirectional in which the sender is both the subject and also the object of the message s/he has sent.

Then what is competence? To some extent, the equivalent of the word is the ability. Hence, the communication ability is the one that a person has to exchange information or express their thoughts and feelings, which is in concordance with the ultimate goal of foreign language teaching to the effect that it is to enable the learners to use the target language in life or work where necessary (Wang, 2000). It is naturally reminiscent of the interactional view of language by La Forge: language is people; language is persons in contact; language is persons in response (La Forge, 1983.). Similarly, communicative competence is "the ability to function in a truly communicative setting - that is, in a dynamic ex-change in which linguistic competence must adapt itself to the total informational input, both linguistic and paralinguistic, of one or more interlocutors" (Savignon, 1972). These quotations simply emphasise the interactional use of the language, i.e. the exchange of information or the expression of the thoughts and feelings among people in the real life. What Krashen (2006) states may summarize what the experts have covered about communicative competence. That is "language learning, as the acquisition of communicative competence, is now defined as the expression, interpretation and negotiation of meaning between two interlocutors or between a text and its readers".

\section{This Study}

Based on the above understanding of communicative competence, English teachers should design their English class in the way that is helpful to cultivate student's communicative competence effectively. In the early 1990s, it was advocated that Communicative Language Teaching (CLT) be applied to English teaching in China. And the 
fact is that people are trying to use CLT so as to create opportunities for students to speak Englsih, especially in cities. However, it has always been a hot topic that a middle school graduate, who starts learning English at a very young age, usually around 7 years old, and has a history of learning English at least ten years, is not able to make a successful communication with those from English-speaking countries. This study aims at elaborating the cultivation of learners' English communicative competence with a view to finding out what affects the cultivation of communicative competence.

\subsection{Rationale for the Study}

For making sure of the factors that have affected the cultivation of learners' communicative competence so as to have a better understanding of communicative competence and make a further study of successful cultivation of learners' communicative competence, an investigation was made among several senior middle schools in three areas in Anhui province. The investigation was made into altogether 9 middle schools of three levels in three areas which are located respectively in the northern Anhui, southern Anhui and central Anhui. They are Huaibei, a city of coal mines in northern Anhui, Wuhu, an economically-and-culturally-developed city along the Changjiang River in southern Anhui and Hefei, the capital of Anhui. The chosen schools can, in great part, represent those in China regarding teaching and educating practice.

\subsection{Subjects}

Altogether 36 senior middle school teachers, including 9 headmasters/headmistresses, 4 of whom are English teachers, received interviews and about 400 students were asked to do a questionnaire.

\subsection{Instrument}

Questionnaire and interview were employed to collect data. The questionnaire was done among the students of Senior Three who still have about one more year of learning to finish their middle schooling. Mp3 or other recording instruments were employed to record the interview.

\subsection{Procedure}

The questionnaire was designed in Chinese around students' oral and written English with a view to examining their communicative competence. For every school, about 50 students of medium level were asked to do the questionnaire. Before they started, they were told the importance of their doing the questionnaire. They were also asked to do the questionnaire at their ease. The questionnaires were collected at most 15 minutes later when they finished them. Altogether 396 effective questionnaires were collected.

The interview was done individually. The questions were not given to the interviewees before hand with the purpose of getting authentic and true report of what they were doing in English teaching practice. Totally 27 senior middle teachers and 9 headmasters/headmistresses received the interview.

\section{Results}

\subsection{Teachers}

Both teachers and headmasters/headmistresses were interviewed with the questions as follows:

a. How many periods are allotted to English subject in the first two years?

b. How many periods are set specifically for listening and speaking?

c. Do teachers often apply communicative language teaching approach in English class?

d. Do they have any extracurricular activities for cultivating students' communicative competence?

e. How many students take part in the extracurricular activities?

f. What do you think is the most important in teaching and learning English?

g. When do they usually start review for the College Entrance Examination?

h. What do they do for reviewing?

The New English Curriculum Standard revised in 2003 suggests that 4 periods be set for English subject every week. The answers to Question a are that 4 periods a week are allotted to completing textbook in the first two years and that every school sets up more or less extra period especially in the first year for English but the purposes differ from school to school. 
Table 1. Extra period(s)

\begin{tabular}{lll}
\hline School(s) & Extra period(s) & Purpose \\
\hline 5 & more than 1 & Enlarging vocabulary \\
& & Improving grammar \\
& & Improving writing \\
\hline 4 & more than 1 & Completing tasks in textbooks \\
\hline
\end{tabular}

For Question b, no classes are specifically set for listening and speaking, but there are listening and speaking activities which are done in accordance with the design of the textbooks. For Questions c, d and e, the interviewed teachers almost offered the same answers: communicative approach is a good way to activate the students in English class, but they can not afford it because they have to keep the same teaching plan with one another. All the schools organize some extracurriculum activities, like English speech contest and English songs contest, for creating opportunities for the students to cultivate their communicative competence. The results are that only few students take part in speech contest and that the students show great interest in English song contest but with more interest in the rhythm and tune of the songs.

The answers from all the interviewees to Question $f$ are almost the same: vocabulary is the utmost important part in English teaching and learning. Table 1 also tells us how much work has been done about vocabulary. At least 2 schools report that right in the first year of senior middle schooling, students become tired of learning English just because they do not know enough English words. And the teachers also complain that the textbooks for junior English fail to prepare the students enough words for senior English learning while the textbooks for senior English, which have too many new words, fail to have a close link with junior English textbooks.

Almost all the 9 schools start the revision at the end of the second senior year exactly after the graduating examination, i. e., they spend at least one year doing the revision for the College Entrance Examination, focusing on listening strategies, reading strategies, and writing strategies, grammar and vocabulary. The main contents of the revision are lecturing on grammar and vocabulary, doing exercises and simulation papers.

\subsection{Students}

The questionnaire contains 43 tasks concerning different abilities. The students are asked to put them into four different categories according to their own abilities: 1) I can do this easily; 2) I can do this in normal situation; 3) This is what should be enhanced right now; 4) This is what I will learn to accomplish in the future. The tasks chosen by the minimum percentage of $25 \%$ among all the students are listed respectively in the tables below.

Table 2. I can do this easily

\begin{tabular}{lcc}
\hline Tasks to be performed & Number & Percent \\
\hline I can ask somebody to repeat. & 229 & $57 \%$ \\
I can fill in the form concerning my personal information. & 123 & $31 \%$ \\
I can write greeting cards. & 102 & $26 \%$ \\
I can write a note to tell somebody where to meet. & 105 & $27 \%$ \\
I can write a self-introduction in simple English. & 173 & $44 \%$ \\
I can understand the messages on how to get to some place & & $29 \%$ \\
and the relevant vehicle that I shall take. & 115 & $31 \%$ \\
I can understand the price, time and numbers as mentioned. & 124 & $41 \%$ \\
I can understand such contents as the name of a person, & 164 & $29 \%$ \\
a place and the age carried in the newspaper. & 114 & \\
I can understand postcards and greeting cards in English. & & $26 \%$ \\
Orally, I can make an apology and can accept or reject & 104 & $28 \%$ \\
apology by other people. & & 112 \\
I can orally respond to the feelings of other people, & & \\
e.g. surprise, happiness, excitement and sadness. &
\end{tabular}


Table 3. I can do this in normal situation

\begin{tabular}{|c|c|c|}
\hline Tasks to be performed & Number & Percent \\
\hline I can fill in the form concerning my personal information. & 142 & $36 \%$ \\
\hline I can write the greeting cards. & 110 & $28 \%$ \\
\hline I can write a note to tell somebody where to meet. & 156 & $39 \%$ \\
\hline I can write a self-introduction in simple English. & 118 & $30 \%$ \\
\hline $\begin{array}{l}\text { I can understand the messages on how to get to some place } \\
\text { and the relevant vehicle that I shall take. }\end{array}$ & 164 & $41 \%$ \\
\hline I can understand the price, time and numbers as mentioned. & 144 & $36 \%$ \\
\hline $\begin{array}{l}\text { I can understand such contents as the name of a person, a } \\
\text { place and the age carried in the newspaper. }\end{array}$ & 139 & $35 \%$ \\
\hline $\begin{array}{l}\text { I can understand the time, place and details of an activity } \\
\text { in a poster. }\end{array}$ & 141 & $36 \%$ \\
\hline I can understand public signs in cities in English. & 158 & $40 \%$ \\
\hline I can understand postcards and greeting cards in English. & 158 & $40 \%$ \\
\hline $\begin{array}{l}\text { I can understand English notes written to me by my friends } \\
\text { and classmates. }\end{array}$ & 178 & $45 \%$ \\
\hline I can greet and say good-bye to my friends in English. & 138 & $35 \%$ \\
\hline I can tell my classmates something and answer their questions. & 105 & $27 \%$ \\
\hline $\begin{array}{l}\text { I can ask my classmates to explain what they are talking about } \\
\text { and express my agreement and disagreement. }\end{array}$ & 138 & $35 \%$ \\
\hline $\begin{array}{l}\text { I can tell my classmates what to do and when to do it. } \\
\text { I can tell others what is important and what is not so }\end{array}$ & 140 & $35 \%$ \\
\hline important. & 138 & $35 \%$ \\
\hline I can understand the advertisements in the newspaper. & 116 & $29 \%$ \\
\hline $\begin{array}{l}\text { Orally, I can extend my invitation to somebody and can accept } \\
\text { or reject the invitation by other people. }\end{array}$ & 170 & $43 \%$ \\
\hline $\begin{array}{l}\text { Orally, I can make an apology and can accept or reject apology } \\
\text { by other people. }\end{array}$ & 125 & $32 \%$ \\
\hline I can write a short article to express my point of view. & 126 & $32 \%$ \\
\hline $\begin{array}{l}\text { I can get the main idea of a passage I am listening to. } \\
\text { I can orally respond to the feelings of other people, }\end{array}$ & 138 & $35 \%$ \\
\hline e.g. surprise, happiness, excitement and sadness. & 145 & $37 \%$ \\
\hline I know how to express my point of view politely. & 163 & $41 \%$ \\
\hline I can write a comment on something. & 111 & $28 \%$ \\
\hline $\begin{array}{l}\text { I can write an article based on my personal } \\
\text { experience, e.g travel. }\end{array}$ & 103 & $26 \%$ \\
\hline I can translate a simple introduction to school. & 166 & $42 \%$ \\
\hline I can order a meal by telephone. & 107 & $27 \%$ \\
\hline I can write a simple purchase order. & 104 & $26 \%$ \\
\hline
\end{tabular}

Table 4. This is what should be enhanced right now

\begin{tabular}{lcc}
\hline Tasks to be performed & Number & Percent \\
\hline I can tell my classmates something and answer their questions. & 117 & $30 \%$ \\
I can control the topic in group discussion and tell them & & $34 \%$ \\
what to talk about. & & \\
I can understand the general idea of a piece of news or a report & 134 & $32 \%$ \\
concerning unexpected events in English TV programmes. & 124 & $31 \%$ \\
I can understand news report in the newspaper. & 116 & $29 \%$ \\
I can describe my experiences. & 102 & $26 \%$ \\
I can write a short article to express my point of view. & & \\
I can follow the oral instructions on how to operate & 123 & $31 \%$ \\
something, for example, an experimental instrument. & 100 & $25 \%$ \\
I can read abridged literary works.. & 124 & $31 \%$ \\
I can analyse orally the merit and demerit of something. & 124 & $36 \%$ \\
I can analyse the cause of something. & 103 & $31 \%$ \\
I can interview somebody by asking him/her questions. & 102 & $26 \%$ \\
I can write a comment on something. & 116 & $26 \%$ \\
I can use different language to write to different people. & 121 & $29 \%$ \\
I can order a meal by telephone. & 112 & $31 \%$ \\
I can report preparedly to the class on a certain topic. & & $29 \%$ \\
I can introduce orally to visitors the features of a place. & 103 & \\
I can tell my classmates the story of a film with which & & $26 \%$ \\
I'm familiar. &
\end{tabular}


Table 5. This is what I will learn to accomplish in the future

\begin{tabular}{lcc}
\hline Tasks to be performed & Number & Percent \\
\hline I can tell my classmates the story of a film with which & & \\
I'm familiar. & 112 & $28 \%$ \\
\hline
\end{tabular}

Table 2 shows only 11 pieces of total 43 tasks can be easily done. The students seem to be more competent in doing understanding and writing tasks. We can see that writing tasks sometimes seem easy for them to complete while oral tasks appear difficult to perform.

Table 3 aims to find out what students can do in normal situation, i. e. in practicing English both in and out of class. When it comes to understanding of what they read, relatively high percentage of students can complete the task. Next comes writing in English. As for the speaking task, there are two groups of performance: 1) when it concerns communicative function, more students can perform it; 2) less students are able to complete the tasks which require the students to process information concerning real life. For instance, only $26 \%$ students can do the tasks as follows: I can write an article based on my personal experience, e.g. travel; I can write a simple purchase order.

Table 4 shows the tasks that the students feel hard to accomplish. Obviously, the list of the tasks becomes longer than the first group. The tasks that most of the students find hard to do are: I can tell my classmates something and answer their questions; I can control the topic in group discussion and tell them what to talk about; and I can analyse the cause of something. Almost all the tasks concern the ability to process information and communicative competence.

Table 5 focuses on the tasks that the students are not capable of doing at present. The result is similar to Item 3 to the effect that the students are not competent enough to do communication concerning real life

\section{Discussion}

\subsection{Learners' Communicative Competence}

As shown in the result, the students can understand both written and oral texts. They can also write better in normal situation. In the similar way, they may have oral communication easily at communicative function level, for instance, accepting or rejecting invitation and expressing agreement or disagreent. They find it hard to communicate both in spoken and written forms when they have to deal with processing information concerning real life. These results are, in great degree, in consistency with teaching practice.

\subsubsection{Learners' Strong Aspects of the Communicative Competence}

That the students have relatively stronger understanding and writing competence is guaranteed by the practice as follows:

- Sufficient attention has been paid to the College Entrance Examination. Because how well a teacher works and how well their students learn are totally dependent upon the students' final scores in the entrance examination, a great majority of time is allotted to vocabulary, listening, reading, and writing which are listed among the testing points in the College Entrance Examination Curriculum. So, all the teaching process is centred around getting high scores in the examination.

- People (educating staff of different levels and students' parents) have a strong conviction that practice makes perfect. Some schools even start to make preparations in one way or another for the College Entrance Examination as early as from Senior One. Students are asked to practice the items in the entrance examination by doing piles of exercises or simulation papers. And what's more, at least one year is spent on preparations for the entrance examination.

- Special attention has been devoted to different aspects of language. From the interview, we know that there is at least one extra period specifically allotted for enlarging vocabulary and improving grammar and writing. Some schools have compiled textbooks for the extra class. Some others have at least made handouts. No matter what aspect of language each material is focused on, one item is never left out, that is reading comprehension, which contributes to the development of reading competence.

It is not without reason for the students to be able to do oral communicative tasks at communicative function level. Communicative functions are also among the testing points in the College Entrance Examination Curriculum. So, equal attention is also paid to practicing these functions in simulation papers. 


\subsubsection{Learners' Weak Point in Their Communicative Competence}

As a result of emphasising high scores in the examination, little time is devoted to speaking activity, which results in that students are weak in oral communication. Besides, it is hard to organise speaking activity in class, for a senior class in China usually consists of over 50 students of multiple levels of aptitude. It is often challenging to organize any activity for practicing speaking. The teachers interviewed reported that students actually enjoy speaking activities in class. The problem is if much time is devoted to speaking activities, only little time can be left to other tasks which they always think are crucial to the examination. More often than not, teachers of the same grade have to keep the same timetable because tests are usually held regularly within a school or within a district. What's more, the College Entrance Examination Curriculum does not include speaking ability. Thereby, speaking activity is only held as a factor of adding colour to the English classroom. Consequently, there is not enough opportunity for students to develop oral communicative competence.

Why are the students not able to accomplish the tasks concerning their real life? From the results of the interview, we may find the reasons for this failure. As the definitions show us, linguistic skills contribute only a part to communicative competence. Widdowson (1978) also found that "the acquisition of linguistic skills does not seem to guarantee the consequent acquisition of communicative abilities in a language." The interview results show too much attention has been paid to the language form. The satisfaction of both teachers and students lie in teachers' presentation of the words and examples on the board and students' successfully taking down the words and examples from the board. Most part of the teaching practice is on explaining sentence structures, analysing text organization and correcting mistakes. There is very little explanation or discusion over information. There is no negotiation of meaning (teachers would be afraid that they are mistaken as unqualified or irresponsible teachers), no students' share of understanding the message in the text and no way for using English to communicate with each other. In a word, there lacks enough input, which results in failure of completing the tasks concerning real life.

\subsection{Elaboration of Cultivating Learners' Communicative Competence}

Based on the above discussion, more work should be done into the teaching and learning so as to develop learners' communicative competence comprehensively.

\subsubsection{Problems in Cultivating Learners' Communicative Competence}

- Language forms vs language functions. At schools of various levels, especially middle schools in China, quite a few English teachers, in order to avoid being 'out', usually deal with words and expressions or the follow-up structures in the showy way, especially in demonstration or competition class, no matter whether the students understand them or not. What they care is that they must catch the fashion of learner-centredness and follow the trend of language use. But in their real teaching practice, they still pay attention only to the language form for the sake of exam-oriented education. Such kind of phenomenon is so widespread in the mainland of China that it cannot be negligible in the language teaching world. The relevant investigation shows that the English teachers understand that it is important to put the language use in the central position, and to put everything else, say, such language forms as words and expressions, grammar and structure in the peripheral position. Yet, in the real teaching practice, they tend to resume the old road. In other words, although they're equipped with the new teaching philosophy, they're still teaching in the traditional way. As mentioned above, there can be several reasons, among which the most important reasons are that many teachers are not capable of understanding the essence of the New Curriculum Standard issued in the year of 2003 by the Ministry of Education of China and that they don't know much how to apply the theory to the practice by building a bridge between the theory mentioned in the curriculum standard and textbooks they're using. As a result, what they think the most important in the curriculum standard is the vocabulary and the communicative functions due to the backwash effect of the College Entrance Examination. On the other hand, there are quite a few teachers, especially young teachers who overemphasise the importance of the language use while they neglect the importance of the language form as the foundation. The result is that the students seem to speak fluently, but such fluency is achieved at the cost of grammatical mistakes. Yes, of course it is advocated nowadays that fluency come first followed by accuracy. But it doesn't mean that fluency should be achieved at the sacrifice of accuracy. According to the investigations done in this study, since the implementation of the CLT in the 90's last century, middle school students, especially those in cities, to some extent, are much better in listening and speaking, yet both of their oral and written productions are full of grammatical mistakes and both are weak in the choice of words, which go against the effort both teachers and students have been making and likewise, against the tenet in CLT that the training in four skills is equally important. Therefore, the implementation of CLT 
entails the necessity of keeping a balance between the linguistic competence and the communicative competence.

- Teaching and learning English for the sake of teaching and learning. Many teachers only focus their eyesight on the teaching and learning English in class. They spend a lot of time dealing with the textbooks in class. And after class they direct their students' eyesight still onto the textbooks by asking them to review what has been learnt or do the exercises from the textbooks. They ignore the extracurricular reading. And a student who learns English for the sake of learning without reading extensively after class may be strong in the relevant exams but surely weak in the integrated quality and finally weak in the communicative competence. A language learner can only get enriched by sipping the nourishment of the target language and its culture from the corresponding magazines, newspapers, novels, etc.

- The exam-oriented education. The current education in the mainland of China is more or less still exam-oriented although the calibre education has been and is being advocated by the educational commissions at all levels. There is a misunderstanding that the annual national entrance exam blocks the way for developing learners' comprehensive competence. Most teachers put these two matters into the positions opposite to each other. They separate cultivation of communicative competence from the entrance examination while these two are in fact closely related. Hence, in the actual teaching, teachers try their utmost in a bid to cater to the exams. It is not difficult to imagine that students taught in this way have relatively poor communicative competence.

- The problem of textbooks. Textbooks for the middle school students overemphasize the language use, interactions, activities, tasks, and ignore the training of the students' linguistic foundations. Personally, the design of the textbooks is going to the extremes. The current English textbooks are completely a breakaway from their traditional counterparts which emphasise the training of the students' linguistic competence. Frankly speaking, the current textbooks are rich and colourful, and humanistic as well for they notice equally cognition and affect at the same time. However, as mentioned above, the fatal shortcoming is that the training of the language form and that of the language use are not in the proper proportion. We should teach the language and teach about the language at the same time.

- In the process of implementing CLT at schools of different levels in China, quite a few English teachers, especially those from middle schools, have difficulty understanding the essence of CLT. They hold the misconception that it would be okay if the teachers in class, after presentation, could provide the students with exercises, exercise-tasks, tasks and activities, etc. having TTT (Teacher Talking Time) been refrained with the ample time going to STT (Student Talking Time) (Zhang \& Wang, 2007) for the sake of practice of the use of the target language. Actually, it is not that easy to implement CLT. The first and foremost is to have the clarifications of misconceptions and have the astute perception of the essence of the communicative competence. And meanwhile, English teachers should notice the crux of training the students' cognitive/academic language proficiency (CALP) and basic interpersonal communicative skills (BICS) (Brown, 1994) Only by giving heed to CALP and BICS can the students have the proper knowledge of language form and the capacity in daily interactions.

\subsubsection{Tentative Suggestions for Cultivating Learners' Communicative Competence}

- Inductive method vs deductive method. In teaching grammar, two methods are often adopted: inductive method and deductive method. Generally speaking, compared with the inductive method, deductive method is traditional. Students taught in this way are deprived of the right to think, to reason, to summarize, to induce the rules by themselves. Every coin has two sides. Students taught deductively can have a clear picture of the grammar they are learning, for every point has been illustrated by the teacher. Due to the point mentioned above, many English teachers, in order to avoid being labeled the "traditional teacher", use as much as possible the inductive method in class, neglecting totally the students' understanding. As a matter of fact, although the inductive method and the deductive method are poles apart, they form a continnum as shown in Figure 2.

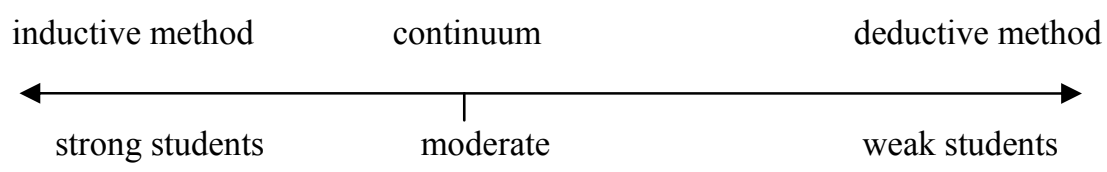

Figure 2.

The weaker the students are, the more use of the deductive method and vice versa. Therefore, if the 
students' level is moderate, neither strong nor weak, the combination is personally advocated. Of course there are such cases when you use the deductive method to teach the weak students, they may get discouraged and frustrated and lose interest completely (Zou, 2010). Hence, there are times when you find that the above suggestion can be reversed.

- Verbal vs. nonverbal. Whenever people talk about communication, it consists of verbal and nonverbal expressions. To some extent, the nonverbal dimension of a language is much more expressive, more subtle than its verbal counterpart. Hence, in the actual language teaching, teachers should pay much attention to the fostering of the students' ability in the nonverbal aspect which includes body language, gestures, eye contact, physical distance, to name a few. "Communicative competence includes nonverbal competence-knowledge of all the varying nonverbal semantics of the second culture, and an ability both to send and receive nonverbal signals unambiguously." (Brown, 1994)

- CLT, as the name is called, is an approach, but not a method. Unlike some of the other methods, it does not tell us concretely what to do, how to do or even why to do in this way. It does not give us a fixed stereotype or paradigm. It only offers us the concept, the idea, or more exactly, a kind of teaching philosophy. Teachers often find it hard to design class of their own. There are two main reasons: 1) Some teachers are used to giving class by following teacher's book for they are not competent enough to do their own design; 2) "teachers and students are held accountable for the curriculum with monthly examinations for all classes in the same grade, culminating in their final year with the high-stakes College Entrance Examination, which determines students' higher education prospects and places considerable emphasis on English grammar". (Duff, (in press).) Therefore, in order to have a real cultivation of the students' communicative competence, it is necessary that the teachers' level should be enhanced so that they really understand the essence of CLT.

\section{Conclusion}

The communicative competence is not only a term but is an umbrella which covers a broad spectrum of language form, language use, verbal and nonverbal dimensions, style and register and culture of the target language as well. In the actual teaching, only if teachers can take into account the above-mentioned points can they say they are cultivating the students' communicative competence. Undoubtedly it is often easier said than done as Stern (1970) put it "nowhere in the world can language teaching claim to have found an easy and final answer to its instructional problems... The continuous questioning of our own efforts and the persistent dissatisfaction among learners do suggest that we are by no means at the end of the road."

\section{Further Research}

This study holds that cultivation of learners's competence and the annual entrance examination is closely related. They should be treated as integrity in the process of cultivating learners's communicative competence and scoring high in the entrance examination. Further research should be made into this issue.

\section{Acknowledgements}

We would like to give our heartfelt thanks to Professor Weicheng Zou for the questionnaire in Chinese he has designed and his directions in the investigation and our thanks should be also extended to the headmasters/headmistresses, teachers and students of the middle schools from the cities of Hefei, Huaibei and Wuhu, Anhui Province, without whose support, the investigation and questionnaire couldn't have been finished.

And our heartfelt thanks should also go to the anonymous reviewers for their suggestions, without which, the paper could not have been finished, either.

\section{References}

Brown, H. D. (1994). Principles of Language Learning and Teaching. Prentice Hall Regents.

Duff, P. (in press). Communicative language teaching. In M. Celce-Murcia, D. Brinton, \& M.A. Snow (Eds.), Teaching English as a second or foreign language (4th ed.). Heinle Cengage. (Feb 26, 2012 version) Retrieved from http://educ.ubc.ca/faculty/pduff/personal_website/Publications/DuffCR_Feb_26_2012.pdf

Fang, Fan. (2010). A Discussion on Developing Students' Communicative Competence in College English Teaching in China. Journal of Language Teaching and Research, 1(2), 111-116. Academy Publisher. Retrieved from http://www.academypublisher.com/jltr/vol01/no02/jltr0102.pdf http://dx.doi.org/10.4304/jltr.1.2. 111-116

Hymes, D. H. (1972). On Communicative Competence. In Brumfit, C., \& K. Johnson (eds), CLT to Language Teaching. Oxford University Press. 
Krashen, S. (2006). The Use of Communicative Competence in a Globa World. Review of Applied Linguistics in China, 2, 30-50.

La Forge, P. G. (1983). Counseling and Culture in Second Language Acquisition. Oxford: Pergamon.

Littlewood, W. (2000). Communicative Language Teaching. Foreign Language Teaching \& Research Press, People's Educational Press \& Cambridge University Press.

Richards, J. C., \& Rodgers, T. S. (2000). Approaches and Methods in Language Teaching. Foreign Language Teaching \& Research Press \& Cambridge University Press.

Savignon, S. J. (1972). Communicative Competence: An Experiment in Foreign-Language Teaching. Philadelphia: The Centre for Curriculum Development, Inc.

Stern, H. H. (1970). Perspective on Second Language Teaching. Toronto OISE Press.

Stern, H. H. (1999). Issues and Options in Language Teaching. Oxford University Press \& Shanghai Foreign Languages Educational Press.

Wang, Qiang. (2000). A Course in English Language Teaching. Higher Education Press.

Widdowson, H. G. (1978). Teaching Language as Communication. Oxford: Oxford University Press.

Wilkins, D. A. (1972). The Linguistic and Situational Content of the Common Core in a Unit/credit System. Ms. Strasbourg. Council of Europe.

Zhang, Yuxiang, \& Wang, Jiling. (2007, January). Learner-centredness. English Teaching professional Issue 48. p. 29. Keyways Publishing Ltd.

Zou, Weicheng. (2010). The lecture for educational linguistics. East China Normal University.

\section{Notes}

Note 1. Figure 1 is taken from Richards, J. C. \& Rodgers, T. S. (2000).

Note 2. The questionnaire which is not published is designed in Chinese by Weicheng Zhou. This is abridged version translated by the authors. 